\title{
Da comunidade à escola: desvelando prá- ticas culturais (in)visíveis dos sujeitos praticantespensantes ${ }^{1}$
}

\author{
Marinaide Lima de Queiroz Freitas \\ Universidade Federal de Alagoas \\ Elisabete Duarte de Oliveira \\ Instituto Federal de Alagoas
}

\section{Resumo}

Este artigo ${ }^{2}$ se insere nas discussões sobre as práticas culturais na Educação de Jovens e Adultos e tem como objetivo compreender como acontecem as práticas culturais dos sujeitos praticantespensantes no espaçotempo que residem e como se relacionam com as práticas culturais manifestas, no cotidiano escolar. Fundamenta-se nos estudos de Alves (2003), Bakhtin (1992) e Certeau (201 1, 2012, 2013). A conclusão apontou a existência de duas práticas culturais (in)visibilizadas no Vale do Reginaldo: a prática do Encontro, como acontecimento reinventado e a prática do Boi Leão, como acontecimento de resistência - constituindo-se como pontos de partida para produção de conhecimentos e de sentidos na escola, acerca dos problemas e diálogos estabelecidos por um grupo ou por pessoas em interação.

Palavras-chave: Docência. Práticas (in)visíveis. Cotidiano escolar. Sujeitos praticantespensantes.

\section{The community to school: unveiling cultural practices (in)visible of subject practoniers and thinkers}

\section{Abstract}

This article is included in the discussions on cultural practices in Youth and Adult Education and aimed to understanding how to place the cultural practices of the subjects "thinkers and practitioners" in living "places and times" and how they relate to the manifest cultural practices in everyday school life. It is based on Alves (2003), Bakhtin (1992) and Certeau (201 1, 2012, 2013) studies. The conclusion pointed to the existence of two cultural practices (in)visualized in the Valley of Reginaldo region: the practice of the "Meeting", as reinvented event, and the "Boi Leão" practice, as a resistance event-establishing itself as the starting point for the production of knowledge and sense at school, about the problems and dialogues established by a group or people within interacting. Keywords: (In)Visible practices. school daily life. Thinkers and practitioners subjects. 


\section{De la comunidad a la escuela: revelando prácticas culturales (in)visi- bles de los sujetos praticantespensantes}

\section{Resumen}

Este artículo está incluido en las discusiones sobre las prácticas culturales en la educación de jóvenes y adultos y tiene como objetivo comprender cómo colocar las prácticas culturales de los sujetos praticantespensantes en el espacio-tiempo de vida y de cómo se relacionan con las prácticas culturales evidentes en la vida escolar cotidiana. Se basa en estudios de Alves (2003), Bakhtin (1 992) y Certeau (201 1, 20 12, 2013). La conclusión se refirió a la existencia de dos prácticas culturales (en)visualizado en la region del Valle de Reginaldo: la práctica de la Reunión, como el evento reinventado, y la práctica del Boi Leão, como un evento de resistencia - constituyendose como el punto de partida para la producción de conocimiento y direcciones en la escuela, sobre los problemas y diálogos establecidos por un grupo o las personas que interactúan. Palabras clave: Prácticas (in)visibles. Rutina de la escuela. Sujetos praticantespensantes.

\section{Introdução}

Este artigo tem como objetivo compreender como acontecem as práticas culturais dos sujeitos praticantespensantes no espaçotempo que residem - no Vale do Reginaldo - situado em Maceió/Alagoas e como se relacionam com as práticas culturais manifestas no cotidiano de uma escola municipal, que faz parte desse mesmo contexto.

Compreendemos que essas práticas culturais são reinvenções e resistências produzidas pelos sujeitos do nosso estudo. Nesse sentido, reinvenção é entendida como a possibilidade de continuidade do processo de criação, de elaboração de sentidos e significados. Essa possibilidade exige incessantemente uma luta, uma oposição, uma resistência (CERTEAU, 2012).

Essa compreensão foi sendo delineada com base nas leituras que realizamos dos estudos no/do/com o cotidiano, que nos favoreceu dialogar com Alves (2003); Certeau (2013), entre outros pesquisadores. Os cotidianos da comunidade do Vale do Reginaldo e da Escola Pública permitiram o nosso encontro com práticas culturais invisibilizadas. 
Nesse sentido, Certeau (2013, p. 38) esclarece-nos que "[...] o cotidiano se inventa com mil maneiras de caça não autorizada" (CERTEAU, 2013, p. 38). É um espaço onde a produção,

É astuciosa, é dispersa, mas ao mesmo tempo ela se insinua ubiquamente, silenciosa e quase invisível, pois não se faz notar com produtos próprios, mas nas maneiras de empregar os produtos impostos por uma ordem econômica dominante (CERTEAU, 2013, p. 39).

Nessa perspectiva, compreendemos as produções/práticas que estavam (in)visíveis nos loci do estudo. Isso aconteceu porque houve uma "intimidade" com as nossas idas e vindas e que foram construídas com o tempo, numa relação com os sujeitos praticantespensantes, no cotidiano vivenciado.

Alves (2003) nos explica que esse cotidiano se reinventa a partir dos usos dos praticantespensantes. Para a autora, os cotidianos são os espaços dos acontecimentos culturais, que não se repetem, tampouco estão sujeitos a obviedades.

Este artigo organiza-se em quatro partes. Na primeira, refletimos sobre 92 as práticas culturais (in)visíveis com base em Alves (2003), Certeau (2013); na segunda, comentamos sobre os sujeitos narradores praticantespensantes da Comunidade Vale do Reginaldo, no processo de produção dessas práticas; na terceira, analisamos os acontecimentos de duas práticas culturais, vivenciadas, no espaçotempo do referido Vale; e por último, na quarta parte, analisamos os acontecimentos manifestos no cotidiano da escola, que se relacionam com as práticas culturais dos sujeitos praticantespensantes desse cotidiano.

\section{As práticas culturais (in) visíveis}

Entendemos, como práticas culturais (in)visíveis, aquelas que ocorrem no sentido de subverter a ordem socioeconômica vigente e que se constituem como "maneiras de fazer" culturas que:

Não rejeitam ou modificam, diretamente, a cultura difundida e imposta pelas elites produtoras de linguagem, mas que, subverte a maneira de usá-las, tornando seus fins e suas referências estranhas ao sistema do qual não [se pode] fugir (CERTEAU, 20 1 3, p. 39). 
A manifestação dessas práticas é possível pelas "[...] táticas de consumo, engenhosidades do fraco para tirar partido do forte [... ]" (CERTEAU, 2013 p. 44 e 45). Segundo o autor, essa tática é concebida como um "[...] cálculo que não pode contar com um produto nem, portanto, com uma fronteira que distingue o outro totalmente visível. A tática só tem por lugar o outro". Esse outro que produz um discurso ideológico (BAKHTIN, 1992), situado em um espaçotempo de poder e é questionado pelos sujeitos, situados em outros espaçostempos; por isso, conseguem proferir uma contrapalavra e estabelecer a dialogia.

Esses sujeitos supostamente passivos usam táticas que dependem do espaço e do tempo que são tão interligados e dependentes que se tornam "uno", espaçotempo. Nessa unicidade, as táticas apresentam-se na forma de práticas que têm continuidades e permanências consentidas pela memória dos sujeitos. A memória permite que os sujeitos, em um espaçotempo, manifestem suas práticas culturais devido a essa capacidade em "[...] acumular experiências passadas e inventariar" (CERTEAU, 2013, p. 146 e 149) outras possíveis. Dessa forma, as práticas culturais invisíveis "[...] escapa[m] ao poder visível".

É a partir dessa discussão sobre o (in) visível, táticas, espaçotempo e dialogicidade que aprofundamos nossa compreensão sobre práticas culturais que se materializou no corpus deste estudo, advindo de narrativas dos sujeitos praticantespensantes da Comunidade do Vale do Reginaldo, situada no município de Maceió, no Estado de Alagoas.

Essa (in)visibilidade das práticas culturais foi-nos sendo desvendadas, paralelamente no trabalho de campo, por meio das discussões de Alves (2003) e outros pesquisadores, que nos ajudaram a entender as práticas culturais como acontecimentos. Assim, o cotidiano é carregado de práticas produzidas em espaços sociais e os sujeitos são produtores praticantes de cultura(s). Fomos entendendo, também que,

O primeiro movimento necessário para se conhecer os nossos cotidianos é o de compreender que precisamos aceitar as tantas teorias aprendidas, sobretudo como limite e não só como potencialidade em nossas pesquisas, na medida em que elas foram 'construídas' negando a existência desses cotidianos e dos conhecimentos que neles são tecidos (ALVES; GARCIA, 2008, p. 12, grifo nosso). 
Da comunidade à escola: desvelando práticas culturais (in)visíveis dos sujeitos praticantespensantes

Isso acentuou ainda mais nossa curiosidade epistemológica de estarmos na comunidade do Vale do Reginaldo e compreendermos práticas culturais (in)visíveis que vêm reinventando-se em seu contexto situacional.

\section{Os sujeitos narradores praticantespensantes}

Na tentativa de buscarmos os sujeitos narradores praticantespensantes da comunidade do Vale do Reginaldo, que contribuíssem para conhecermos e aprofundarmos a história do local, por ausência de memória escrita nos órgãos oficiais do Estado de Alagoas, bem como das práticas culturais, sentimos a necessidade de mapear as agências de letramento existentes na localidade como: Associação de Moradores; Escolas Públicas e as Igrejas Católica e Evangélica, entre outras.

Nesse propósito, observamos que os moradores gostavam de conversar e percebemos a riqueza que seriam as sessões conversas, que pretendíamos realizar e realizamos com eles, em suas casas ou em ambientes de trabalho, como um procedimento de produção de dados, que duraram de 20 a 60 minutos e aconteceram após agendamentos prévios.

94 Ousamos, como anônimas, fazermos abordagens às pessoas, especificamente, às de mais idade que guardam, nas suas memórias, as recordações das épocas festivas acontecidas no Reginaldo, para compreendermos a partir do movimento local, o dia a dia das pessoas. Compreendemos, naquele momento, que a Escola Municipal que tínhamos localizado no mapeamento seria também lócus da pesquisa.

A referida Escola funciona nos três turnos, e está situada num lugar estratégico, ou seja, na entrada do Vale do Reginaldo, pelo lado do bairro chamado Poço. Na sua matrícula, no horário noturno, identificamos que mais de $90 \%$ dos estudantes eram moradores do Vale. Esse estabelecimento de ensino, nos períodos matutino e vespertino, atende às crianças do Ensino Fundamental dito regular e, no noturno, os anos iniciais e finais do Ensino Fundamental da Educação de Jovens e Adultos (EJA).

Na Escola, o nosso contato foi com os estudantes da EJA e, nesse contexto, conhecemos a estudante Dona Aparecida (2012), com a qual tivemos uma longa conversa informal, quando falamos do objetivo do estudo, que além de conhecermos as práticas culturais da localidade, necessitávamos conhecer a história do Vale. 
A interlocutora nos indicou a Associação de Bairro do Vale do Reginaldo, que já constava no nosso mapeamento, e se prontificou a fazer contato com o seu presidente, o Sr. Fuscão, no sentido de solicitar que nos recebesse. Com a permissão concedida, a partir da intermediação realizada por Dona Aparecida (2012), fizemos nosso primeiro contato com o Presidente, via telefone, e agendamos um encontro na referida Associação. Nesse encontro, fomos atendidas por um dos seus membros Sr. Marcos, que ficou por nós conhecido como Sr. Marcos da Associação.

Na ocasião, informamo-lo sobre o que era o trabalho que pretendíamos realizar e qual nosso objetivo de estarmos na Comunidade, bem como a possibilidade de agendarmos sessões conversas com os moradores, caracterizadas como encontros abertos de coleta de dados, afastando-se da formalidade da técnica da entrevista (ALVES, 2003). A partir desse primeiro contato, foram localizados outros sujeitos que se dispuseram a narrar a história, conforme enfatizamos a seguir.

Nesse sentido, tendo como intenção conhecer e aprofundar a história local em relação às práticas culturais, definimos que os sujeitos para nos contar essas histórias deveriam ser os moradores mais antigos ligados às organizações das manifestações culturais locais.

Esses sujeitos protagonistas da história sobre o Vale do Reginaldo e suas práticas culturais são moradores articulados diretamente aos acontecimentos do lugar, a exemplo do Sr. Marcos da Associação (2013), que tem 45 anos e, há 30 anos, é residente no Vale. Conhece muito da história e guarda documentos, a exemplo de registros não oficiais, mas, segundo eles, são significativos para a comunidade. Sr Marcos da Associação (2013) conhece muitos outros moradores e foi nosso elo inicial com outros sujeitos, também antigos e que, assim como ele, puderam narrar a história que ora contamos.

A conversa com o Sr. Marcos da Associação (2013) foi muito espontânea. Ele narrou que, no Vale, as iniciativas culturais estavam atreladas às Igrejas Católicas e Evangélicas. Essas Instituições realizam os ensaios e fazem apresentações nas próprias Igrejas de pastoril, teatro, coral e acrescentou que "Antigamente tinha as cavalhadas, durante a festa de Senhor do Bonfim, mas hoje em dia [referindo-se ao ano de 2013], não se vê mais isso". E complementou de forma enfática: "O que todo mundo achava mesmo bonito de se ver eram as apresentações do Boi" (SR. MARCOS DA ASSOCIAÇÃO, 2013 ). 
Da comunidade à escola: desvelando práticas culturais (in)visíveis dos sujeitos praticantespensantes

Enfatizamos que a conversa com o Sr. Marcos da Associação (201 3) fluiu. Ele foi o grande mediador de outros encontros com outros moradores e de outras narrativas, apresentando-nos a outros interlocutores como: um outro Sr. Marcos que o denominamos de Sr. Marcos 1 (2013), Dona Dé (2013) e ao Sr. Paulo (2013). Narrou sobre o trabalho dessas pessoas na comunidade e estabeleceu a confiabilidade entre nós e os sujeitos interlocutores, para garantir, também, o entendimento sobre nosso interesse nos encontros e nas conversas que tivemos.

O Sr. Marcos 1 (2013) tem 53 anos, é dono de uma mercearia na localidade e nos recebeu no seu próprio ambiente de trabalho, muito à vontade, sentado em uma cadeira de balanço que dispunha dentro da "venda", linguagem própria dos moradores ao se referirem à Mercearia. Pelo seu estabelecimento comercial, circulam muitas pessoas que fazem compras, sentam na calçada para conversar ou, simplesmente, passam pelo lugar.

A interlocutora Dona Dé (2013), também moradora antiga, com 59 anos, chegou adolescente ao Vale do Reginaldo. A sessão conversa com ela aconteceu na varanda da sua residência. Antes de iniciarmos a conversa, recebemos o convite para conhecermos a sua casa e o canto, expressão utilizada ao se referir ao local onde expõe os artesanatos que produz, tais como: bolsas e colares de tecidos de chita e as miniaturas do Boi Leão.

Trouxe-nos histórias sobre a prática cultural do referido Boi e muitas críticas à desvalorização, por parte das autoridades públicas, às práticas e produções artesanais dos sujeitos do Vale. Para Dona Dé (2013), "Se o que é feito por aqui, fosse feito em outros lugares melhores da cidade, era mais valorizado [...] mas como é do Vale [...] nada presta" referindo-se aos trabalhos, pinturas, esculturas, peças de decoração, acessórios femininos, produzidos pelos moradores e que não são divulgados. Como moradora antiga, exercitou muito a sua memória sobre o lugar.

Dessa forma, confirmou as histórias contadas pelo Sr. Marcos 1 (2013), sobre as festividades do lugar e deu ênfase às do Sr. Paulo (2013), que comentamos na sequência, sobre o Boi Leão. A interrupção das festividades juninas, das apresentações do Boi Leão e as mudanças estruturais no Vale do Reginaldo apontaram para práticas culturais que continuam vivas na memória dos sujeitos e dessa forma são reinventadas, e outras também são criadas. 
Assim como o Sr. Marcos da Associação (2013), o Sr. Paulo (2013), outro sujeito entrevistado, à exceção dos outros, é mais jovem, tem 26 anos e é também conhecido no Vale do Reginaldo. Nasceu no lugar e é um sujeito que interage com os moradores mais novos e com os mais velhos. Inferimos que essa interação decorre da sua relação com o grupo do Boi Leão do qual é membro fundador e, pelo trabalho desenvolvido na rádio comunitária. Por meio das narrativas desse interlocutor, conhecemos a prática cultural do Boi Leão, que comentamos neste artigo e a história de resistência dos sujeitos dessa prática, para não aderirem ao processo de folclorização que outros grupos vivenciam na cidade de Maceió.

Essa prática cultural aconteceu por muitos anos no Vale do Reginaldo e que parece adormecida. Com esse interlocutor, tivemos quatro sessões conversas. O Sr. Paulo (2013) também se tornou um acompanhante em nossas visitas ao Vale do Reginaldo. Nossa presença na comunidade era bem-vinda e conferimos aos Senhores Paulo (2013) e Marcos da Associação (2013) esse mérito. Essa acolhida foi muito importante para que as conversas fluíssem sem medos em fazer os anúncios e as denúncias sobre os acontecimentos do lugar. Esses sujeitos são,

[...] narradores praticantespensantes traçando/trançando as redes dos múltiplos relatos que chegaram/chegam até nós, neles inserindo, sempre, o fio do nosso modo próprio de contar [...] (ALVES; GARCIA, 2008, p. 274).

Portanto, a partir dessas narrativas passamos a comentar sobre as práticas culturais que detectamos no Vale do Reginaldo.

\section{A prática cultural da reinvenção: o Encontro}

É possível compreender que, apesar de realizada apenas uma parte da obra de revitalização do Vale do Reginaldo, as mudanças estruturais já estão influenciando o dia a dia dos seus moradores de forma significativa, sobretudo, no que se refere às tradições culturais, manifestadas durante as festividades. Entretanto, ao compreendermos a cultura enquanto produção de sentidos e significados, afirmamos que outras práticas foram sendo reinventadas pelos seus moradores, a exemplo da narrada pelo Sr. Marcos da 
Da comunidade à escola: desvelando práticas culturais (in)visíveis dos sujeitos praticantespensantes

Associação (2013), ao falar da sua relação com a história da comunidade em questão:

Eu nasci no Reginaldo, pegava peixe, sardinha, pitú no riacho. Era um lugar muito tranquilo, poucas casas, muitos sítios. Lugar de muita conversa dos moradores [...] $\bigcirc$ riacho do Reginaldo era muito limpo e um ponto de encontro, porque todos lavavam roupa no riacho. Isso há 37 anos (SR. MARCOS DA ASSOCIAÇÃO, 2013, grifo nosso).

A narrativa caminha na mesma direção do depoimento de outra moradora local, Dona Dé (2013) que revela uma prática cultural que foi reinventada, recentemente, pelos moradores, apesar das modificações sofridas no referido Vale:

Aqui todo mundo conversa um com o outro. Às vezes tem umas brigas [...] quando se passa muito tempo junto termina se arranhando (risos). Mas basta uma necessidade e estamos juntos. Também a gente quando vai chegando do trabalho tem que bater o ponto na barraca da macaxeira, ou esquina do seu Marcos [MARCOS 1] (DONA DÉ, 2013, grifo nosso).

A barraca da "macaxeira" tornou-se o local de Encontro mais permanente e ocupou o espaço da "beira" do riacho lexpressão comum falada pelos que lá habitam), onde já não é possível reunirem-se para as conversas sobre os acontecimentos do dia a dia. $\bigcirc$ mais importante é que o Encontro permanece como uma reinvenção de uma prática cultural que existiu/existe. É que a barraca da macaxeira e outros locais de encontros surgem, a exemplo das calçadas nas esquinas, para tratar dos acontecimentos da comunidade. Isso se repete na sala de aula de EJA, que observamos, antes da chegada da professora e nos intervalos, considerando que a maioria dos estudantes é da mesma comunidade.

A narrativa do morador Sr. Marcos da Associação (2013), mencionada anteriormente, trouxe-nos o conhecimento sobre uma prática cultural reinventada, que ainda permanece viva na memória dos moradores do Vale do Reginaldo. É que os jovens moradores da localidade não viveram a época dos encontros à "beira" do riacho. Mas eles a reinventam a partir das lembranças dos adultos e dos idosos, advindas das memórias coletivas e individuais, situadas em outro espaçotempo, compartilhado por todos. 
Os sujeitos moradores do Vale do Reginaldo também, narradores praticantes, vão reconstruindo suas histórias, e dão sentido às suas memórias que são herdadas não apenas de outros sujeitos, mas também, de outros espaçostempos, de outras memórias ressignificadas e reinventadas. Essas memórias vão tecendo as táticas dos moradores, que, de uma forma quase que imperceptível, invisível, subvertem a ordem que intenciona a (des)caracterização de um lugar.

No acontecimento da prática cultural do Encontro, é desencadeado o processo interacional verbal e social, considerando esse processo ocorrer "[...] dentro de níveis ou graus de sociabilidade" (FREITAS, 1999, p. 54) desses sujeitos. No caso dos moradores do Vale do Reginaldo o grau de interações verbais é alto, incidindo em um maior grau de consciência desses indivíduos que "[...] por sua vez, implicará um maior grau de constituição dos indivíduos sociais; com isso define-se que os sujeitos são socialmente orientados" (FREITAS, 1999, p. 54).

A prática cultural do Encontro pode acontecer em outros espaços, em outras comunidades, com outros sujeitos e representarem sentidos diferentes do que nós observamos no Vale do Reginaldo. Conhecemos, por meio de nosso contato, a origem dessa prática em um espaço específico, entre sujeitos orientados pelo mesmo contexto social. Isso nos levou ao entendimento de que,

Uma demanda que surge no interior de uma cultura específica se expande, e seu elo com a cultura de origem se transforma ao ser obrigada a negociar seu significado como outras tradições dentro de um 'horizonte' mais amplo que agora inclui ambas (HALL, 2013, p. 931.

Nesse contexto, foi a prática do Boi que nos trouxe aspectos de compreensão de uma prática cultural de resistência que produz sentidos diversos, as culturas do Boi. São vários os grupos de Boi oriundos do Vale do Reginaldo. Mas, o Boi Leão faz parte da lembrança e dos comentários de todos os interlocutores quando a discussão dessas conversas pautava sobre a cultura local. E nesse sentido, tratamos na sequência, da prática cultural do Boi Leão, intencionando compreender sua relação com a comunidade, os aspectos de resistência para que não se torne uma simples manifestação folclórica. 


\section{A prática cultural da resistência: o Boi Leão}

Boi é uma manifestação cultural encontrada em quase todos os Estados da região Nordeste. $\bigcirc$ Livro Didático (LD) de autoria de Souza, Meneghello, Passos, Pinela, Giaretta, Bellusci e Sosso (2009), adotado pelas escolas municipais de Maceió, na EJA, do qual tivemos acesso trata a Festa do Boi como uma manifestação do folclore brasileiro. Nesse LD, a Festa do Boi tem origem nas fábulas rurais. A mais conhecida é a do pai Francisco e da mãe Catrina. Durante a gravidez, mãe Catrina sente o desejo de comer a língua do Boi mais cobiçado da sua região. Comovido pelo desejo, pai Francisco arranca a língua do melhor Boi do seu patrão.

Nas apresentações, os grupos de Boi representam a história de um Boi furioso, que luta contra as investidas de pai Francisco. A mesma inspiração para as representações, mas em cada região uma prática diferenciada, ressignificada a partir dos referenciais culturais locais.

Nas narrativas dos moradores do Vale do Reginaldo, o Boi não é tratado como uma manifestação folclórica, e sim como uma prática cultural, um acontecimento referenciado pela singularidade do seu lugar com traje,

100 batuque, música e dança próprios, sentidos formulados e representados pelos sujeitos da comunidade. Na tentativa de compreendermos melhor a prática cultural do Boi no Vale do Reginaldo, mantivemos o seguinte diálogo com o morador e membro do grupo do Boi Leão, na rádio comunitária do Vale do Reginaldo,

Entrevistadora: Boa tarde, então você é o homem do Boi? (risos) Sr. Paulo: Boa tarde! É o povo que me chama assim.

Entrevistadora: Você poderia contar essa história do Boi aqui no Vale do Reginaldo?

Sr. Paulo: $\bigcirc$ Boi Leão é o mais conhecido do Reginaldo. Já têm uns três anos que não saímos mais no carnaval. Mas, todo mundo se lembra dele e pergunta quando vamos voltar (SR. PAULO, 2013).

Este trecho da fala nos remete à explicação de Certeau (2011) sobre a memória alimentar dos sujeitos em um sentido positivo, visto que,

alimento escolhido, permitido e preferido é o lugar do empithamento silencioso de toda uma estratificação de ordens e 
contraordens que dependem ao mesmo tempo de uma etno-história, de uma biologia, de uma climatologia e de uma economia regional, de uma invenção cultural e de uma experiência pessoal. Sua escolha então depende de fatores por sua vez dependentes das determinações objetivas do tempo e do lugar, da diversidade criadora dos grupos humanos e das pessoas, da contingência indecifrável de micro-histórias (CERTEAU, 2011 , p. 250).

Para Certeau (2011):

Comer serve não apenas para manter a máquina biológica do nosso corpo, mas também para concretizar um dos modos de relação entre as pessoas e o mundo, desenhando assim uma de suas referências fundamentais no espaço-tempo (CERTEAU, 2011, p. 250).

Nesse sentido, lembrar e falar sobre o Boi Leão é uma das formas dos sujeitos moradores se entenderem culturalmente no Reginaldo, compreenderem através dessa prática cultural, seu pertencimento local. Essa relação da história do sujeito com a existência da prática cultural do Boi Leão também é evidenciada pelo comportamento do morador durante a conversa. É importante destacar o sorriso no rosto do membro do grupo do Boi Leão. E sentindo-se muito à vontade, no meio do diálogo acima expresso, convidou-nos para continuar a conversa em sua casa.

Ao adentrarmos à sua residência, encontramo-nos diante de um espaço que poderíamos chamar de "Museu" do Boi Leão, contendo em exposição permanente: fotos, troféus, recortes de jornais, miniaturas, instrumentos de batucadas e a cabeça original do Boi Leão afixada em uma das paredes da sala. Diante desse acervo, na explicação de cada peça, uma história contada e confirmada por gestos de outros moradores que nos acompanharam na visita à residência do Sr. Paulo (2013).

Na narrativa do nosso interlocutor ao contar a história do Boi Leão, observamos que a mesclava com a sua própria história. É que a história do Boi Leão é também a história daquele sujeito. Uma história que ele foi protagonista e contribui para o seu processo de identificação cultural e pessoal revelados, sobretudo, no conflito, na resistência em não esquecer o que é próprio do lugar onde vive e não se render às exigências da indústria cultural que tenta homogeneizar as práticas culturais dos sujeitos. Ao apresentar-nos a miniatura do Boi 
Leão, Sr. Paulo (2013) relatava as características de cor, brilho, materiais que diferenciava aquele Boi dos demais.

A resistência em manter a prática cultural, a partir das produções de sentidos dos sujeitos envolvidos, é evidenciada no trecho da narrativa que se segue:

Entrevistadora: E o que houve? Por que vocês pararam?

Sr. Paulo: Muita gente acha que foi intriga entre os outros grupos. Mas, não foi nada disso não. Faz parte da festa do Boi, quando encontra outro Boi acontecer aquela rivalidade, eles se estranham. Mas é só ali, durante a apresentação. $\bigcirc$ que aconteceu de verdade foi que o grupo do Boi leão desanimou com as competições.

Entrevistadora: Como eram as competições?

Sr. Paulo: Aconteciam uma vez por ano, na época do carnaval, organizadas pela prefeitura. Só que eles acham que o Boi alagoano é igual ao do Maranhão. No Maranhão a festa do Boi parece o desfile de escola de samba (SR. PAULO, 2013).

A crítica do depoente às competições é uma forma de resistir ao que 102 Certeau (2012) chama de folclorização,

Uma vez que a capacidade de produzir é na realidade organizada segundo racionalidade ou poderes econômicos, e as representações coletivas se folclorizam. As instâncias ideológicas metamorfoseiam-se em espetáculos. Excluem-se das festas tanto o risco como a criação (a aposta pelo menos mantém o risco). As fábulas para espectadores sentados proliferam nos espaços de lazer que tornaram possível e necessário um trabalho concentrado e 'forçado' [...] o crescimento do 'cultural' é a indexação do movimento que transforma o 'povo' em 'público' (CERTEAU, 2012, p. 198, grifo do autor).

Compreendemos que a existência do Boi Leão na comunidade do Vale do Reginaldo garante a ação do povo e não o transforma em público passivo. É uma prática cultural cuja expressão é da resistência à homogeneização cultural, onde os sujeitos praticantes possuem autonomia e são autores na vida, na história, no lugar. Podemos identificar essa autoria quando o Sr. Paulo (2013) enfatiza que, 
Primeiro a gente não precisa de dia e hora para se exibir [...] A gente sai na rua e as crianças tudo atrás. Quando encontramos outro grupo, começamos a representar. Depois as nossas roupas, nossos trajes são costurados por aqui mesmo, todo mundo dando palpite. A batida da nossa batucada não é a mesma do Boi do Maranhão, nem os nossos instrumentos. É uma beleza o batuque moça (sons emitidos do batuque com a mão em uma mesa) (SR. PAULO, 2013).

No sentido de complementar o diálogo, indagamos:

Entrevistadora: Como você consegue estabelecer essa diferença de batuque?

Sr. Paulo: Meus ouvidos dizem na hora. Cresci ouvindo isso não tem como errar (SR. PAULO, 2013).

O interlocutor Sr. Paulo (2013) explica a diferença entre as práticas culturais de Alagoas e do Maranhão usando os sons do batuque, revela que as diferenças entre as práticas "[...] não pode ser dita nem ensinada, mas deve ser praticada" (CERTEAU, 2013, p. 140). E é essa prática que faz com que o Boi seja o que é. Fica explícito que não podemos tratar a prática cultural como um patrimônio cultural e submetê-lo apenas à existência de uma tradição. Essa compreensão, como tradição, revela uma fragilidade para a defesa de uma concepção de cultura enquanto produção de sentidos. Por essa razão, Certeau destaca que,

A reivindicação cultural não é um fenômeno simples. $\bigcirc$ caminho tomado e seguido normalmente por um movimento que resgata sua autonomia é exumar, sob manifestação cultural que corresponde a um primeiro momento de tomada de consciência, as implicações políticas e sociais que aí se acham envolvidas (CERTEAU, 2013, p. 148).

Nessa direção é que caminha a fala do Sr. Paulo (2013), pois há um processo de tomada de consciência, visto que, apesar de as apresentações do Boi Leão estarem suspensas nas competições, os sujeitos envolvidos no grupo não eliminaram sua referência cultural. Trata-se dessa forma de uma luta política para que a prática cultural se afirme. Trata-se ainda em compreender que, 
Da comunidade à escola: desvelando práticas culturais lin/visíveis dos sujeitos praticantespensantes

A sociedade em transformação alarga-se para integrar o ser em transformação. Nada pode permanecer estável, nesse processo. É por isso que a significação, elemento abstrato igual a si mesmo, é absorvida pelo tema [sentido], e dilacerada por suas contradições vivas, para retornar enfim sob a forma de uma nova significação com uma estabilidade e uma identidade igualmente provisória (BAKHTIN, 1992, p. 136).

Percebemos que esse é o caminho da luta do Sr. Paulo (2013) para garantir a permanência do Boi Leão no Vale do Reginaldo e Dona Dé (20 13 ), artesã, moradora antiga da localidade é uma aliada nessa caminhada, que contribui confeccionando, entre outros trabalhos, miniaturas do Boi Leão e, em sessão conversa na sua residência mantivemos o seguinte diálogo:

Entrevistadora: Boa tarde, Dona Dé! Posso entrar?

Dona Dé: Pode minha filha lapontando para uma cadeira, sinaliza para eu sentar). Senta aí. (Sons de movimento)

Entrevistadora: A senhora conhece o Boi Leão?

Dona Dé: Conheço sim. Quem não conhece por aqui? Mas já faz um tempinho que ele não se apresenta. Mas parece gente, o Boi, todo mundo fala nele, não é esquecido de jeito nenhum (DONA DÉ, 2013).

Compreendemos, na continuidade do diálogo com Dona Dé (20 13 ), que a participação dos moradores nas apresentações do Boi Leão é visível, pois se anunciam claramente como sujeitos integrantes do grupo; e invisível, visto que, apesar de não participarem diretamente, como integrantes do grupo, também são praticantespensantes que usam "táticas", "maneira de fazer" (CERTEAU, 2013) para contribuir com o fortalecimento e existência da prática cultural em questão. Vejamos:

Entrevistadora: A senhora participava das apresentações?

Dona Dé: (risos) Eu não aguento o rojão não. Os mais jovens que aguentam. Eu fico daqui de casa ouvindo as histórias das apresentações e fazendo Boi pequeno para as crianças brincarem. Gosto assim! (DONA DÉ, 2013).

A narrativa de Dona Dé (2013) confirma as histórias contadas pelo membro do grupo do Boi Leão, o Sr. Paulo (2013), ao mesmo tempo reafirma 
que a prática cultural do lugar não é vivida apenas por um sujeito mas materializada na coletividade e presente na memória do grupo. Os diálogos com os moradores apontaram que,

$\bigcirc$ mundo no qual vivemos não está dado a priori. $\bigcirc$ construímos le somos construídos) ao longo de nossa interação com ele. A história individual e singular dos sujeitos é uma deriva de mudança estrutural contingente com as interações experienciadas. Os sujeitos, em processo de coderiva, em processos coletivos vão sendo singularmente marcados e imprimem suas marcas (também singulares) às experiências copartilhadas (SAMPAIO, 2008, p. 16).

É nesse caminho e sendo autores de suas histórias que os sujeitos vão compondo também a história do lugar e a história do Boi Leão, acontecimento, prática cultural "sobrevivente na memória" (PINHEIRO, 2007) dos moradores do Vale do Reginaldo.

\section{A reinvenção e a resistência na Escola}

Assumimos como Tura (2010, p. 156) para quem "A escola é um local privilegiado de troca de ideias, de encontros, de legitimação de práticas sociais, de interação entre gerações, de articulação entre diversos padrões culturais e modelos cognitivos."

E o nosso cotidiano estudado, especificamente, sobre práticas culturais nos fez compreender que,

A cultura é uma noite escura em que dormem as revoluções de há pouco, invisíveis, encerradas em práticas, mas pirilampos, e por vezes grandes pássaros noturnos, atravessam-na; aparecimentos e criações que delineiam a chance de outro dia (CERTEAU, 2012, p. 239).

Os rastros dos pirilampos e dos grandes pássaros noturnos nos chamaram atenção, para dois movimentos que se cruzaram no contexto escolar. Um, é próprio da cultura estabelecida oficialmente às instituições de ensino, que define uma cultura institucional, como observamos no depoimento da diretora da escola: 
Da comunidade à escola: desvelando práticas culturais lin/visíveis dos sujeitos praticantespensantes

A Secretaria [de Educação Municipal] não aceita que a escola coloque outros horários para funcionamento da Educação de Jovens e Adultos, a exemplo dos sábados [...] alegando que a maioria das escolas coloca esse dia letivo como algo fictício. Eles [os técnicos] não aceitam [...]. Embora já tivemos várias atividades bem sucedidas aos sábados, por exemplo, atividades de visitas a outros lugares, trabalho cultural indo à cidade de Marechal Deodoro [primeira capital de Alagoas] (DIRETORA, 2013).

outro é um movimento que sempre chega para questionar o que parecia institucionalizado. Isso porque a escola é embrenhada de várias outras culturas; de trocas e interações, onde os sujeitos desafiam a cultura das normas, dos ritos, dos códigos da linguagem, dos mitos, das sagas e das narrativas (GOMES, 2000), dialogando na busca do que thes faz sentido e thes traz significado. Segundo Torres (2008), a cultura organizacional escolar vai se construindo e desenvolvendo dentro de um "entreposto cultural", isto é, transpassada pelas culturas micro e macrossistêmicas que agem com suas normas e que regulam o lugar e que interferem nessa cultura. Para Tura (2010),

As formas ritualizadas de organização do espaço escolar [...] são processos que indicam aos que frequentam aquele lugar, de que estavam em uma escola, de que há regras a cumprir e um costume sancionado e legitimado (TURA, 2010, p. 159).

Essas formas ritualizadas são estabelecidas nas instituições de ensino e determinam uma cultura escolar que contribui para o controle sobre o funcionamento da escola, conforme destacou a diretora na sua narrativa acima. Mesmo que, naquela escola, houvesse aulas aos sábados, a regra institucional não permitia atender a essa condição, que a difere das demais; dessa forma, torna homogêneo um trabalho que por natureza é heterogêneo, sobretudo, tratando-se da EJA.

Na contramão do que pensam os gestores da Secretaria de Educação Municipal de Maceió, a diretora da escola municipal, que também foi lócus da pesquisa, conforme já anunciamos, revela-nos que o rompimento com a cultura organizacional em termos das atividades culturais que realizaram "[...] são importantes para diferenciar, além de temas e conteúdos de estudo, o currículo da modalidade de ensino na EJA, do ensino dito regular".

Nesse sentido, é importante não negar a "existência de criação, de singularidade, de soluções locais, de invenção curricular, de produção de 
conhecimento anteriormente negligenciado [...]" (OLIVEIRA, 2012, p. 91), que existem na cultura escolar. As nossas idas e vindas ao Vale do Reginaldo e à escola municipal, repetidas vezes, nos fez participar de atividades culturais e compreender as "maneiras de fazer" (CERTEAU, 2013) culturas dos estudantes na escola, como exemplificamos a seguir.

A escola realizou uma atividade com todas as turmas de EJA lanos iniciais e finais), fora do espaço da sala de aula, sobre a temática: Regiões do Brasil. Cada turma trabalhou durante um mês, no espaço da sala de aula, um assunto específico, sobre a referida temática. E para a sua culminância foi organizado, em um sábado, um evento aberto para alunos, familiares e demais pessoas da comunidade, com leituras de textos em voz alta, advindos do trabalho em sala. É importante dizer que atividades semelhantes são realizadas, por iniciativas das Igrejas Evangélicas e Católicas, situadas entre o bairro do Poço e no Vale do Reginaldo, por isso os participantes ficaram muito à vontade, ao vivenciarem a leitura dos textos.

No entanto, no âmbito escolar, foi uma iniciativa de contracultura, uma demonstração de resistência à cultura organizacional escolar instituída, ao realizar uma atividade curricular fora da sala de aula e em um dia considerado não letivo e conseguir um grande público, tanto de alunos, familiares e pessoas da comunidade, destacando-se a presença das mulheres, extrapolando a expectativa dos gestores do estabelecimento de ensino.

A partir da nossa vivência nos lócus da pesquisa, configuramos aquele momento como a prática cultural do Encontro, que saía da "beira" do Riacho Reginaldo, das ruas, das barracas e adentrava a escola. Compreendemos que, por meio do evento, esses grupos negavam a rigidez da cultura organizacional da escola demonstrando ser ela "[... ] um lugar onde se constroem identidades [e] onde se delimitam diferenças [...]" (TURA, 2010, p. 157). Essa construção e delimitação são possíveis pela:

Noção de circularidade entre culturas [que] estabelece, pois, uma mobilidade fundada na inter-relação e na intertextualidade das culturas e subentende movimentos ascendentes e descendentes, que se processam no interior de uma hierarquia de poderes (TURA, 2010, p. 157).

Observamos, também, que os momentos de dispersão que aconteceram por algumas pessoas presentes, durante as apresentações sobre as regiões 
do Brasil, sobretudo, pelos jovens, a partir dos seus referenciais, constituindo-se como momentos de discussão, paralelo ao que estava sendo apresentado. Esses jovens não estavam negando aquele momento, nem a possibilidade de interação com os adultos; estavam atribuindo o sentido e o significado, enquanto grupo, para o acontecimento, em um "[...] influxo recíproco entre cultura subalterna e cultura hegemônica" (GINZBURG, 2006, p. 15).

Esses sujeitos resistiam, assim como o grupo que fazia parte do Boi Leão, ao processo de imposição de uma cultura que não thes faz sentido. Alerta-nos Bakhtin (1992) que,

A significação não está na palavra nem na alma do interlocutor. Ela é o efeito da interação do locutor e do receptor produzidos através do material de um determinado complexo sonoro. É como uma faísca elétrica que só se produz quando há contato dos dois polos opostos (BAKHTIN, 1992, p. 132).

Dessa forma, ficou demonstrado que a cultura escolar desenvolve um processo contínuo de encontros e de aparentes desencontros entre a intencionalidade da cultura organizacional da instituição e as culturas levadas pelos 108 sujeitos. E vai constituindo esse processo na dialogicidade entre os sujeitos que estão em lados opostos e que, por isso causam conflitos, "faíscas" que produzem diferentes significados no contexto escolar.

Os acontecimentos no cotidiano da escola levaram-nos a compreender que, mesmo não encontrando iniciativas oficiais que pudessem fomentar as manifestações das práticas culturais dos sujeitos, elas lá estavam. E foram explicitadas por iniciativas dos próprios estudantes, o que configura a resistência pela aceitação ao espaço formalizado da escola. $O$ que nos pareceu foi que a cultura institucional, ao tentar estabelecer uma ordem, distancia-se da cultura da comunidade. Entretanto, os sujeitos praticantespensantes desencadearam uma produção de práticas que subverteram a ordem oficial da escola.

As práticas culturais (in)visíveis estão em todos os espaços em que os sujeitos praticantespensantes usando táticas interagem, resistem e subvertem. Estavam/estão no Vale do Reginaldo que é um celeiro de práticas culturais da cidade de Maceió e na escola municipal. Ao adentrarmos no cotidiano e deixarmos ser levadas pelos rastros de pirilampos e pássaros noturnos, passamos a enxergar essas práticas. 


\section{Conclusão}

$\bigcirc$ estudo fez-nos compreender que duas práticas culturais (in)visibilizadas no Vale do Reginaldo se relacionam e se manifestam no cotidiano da escola, como acontecimentos mais importantes para os sujeitos praticantespensantes: a do Encontro e a do Boi Leão. Nas práticas dessas culturas, o processo de interação verbal (BAKHTIN, 1992) entre os sujeitos e os grupos sociais foi pressuposto para esses acontecimentos. A palavra e a contrapalavra ditas em um espaçotempo deram vida às práticas culturais (in)visíveis do referido Vale e na escola municipal.

Enfatizamos, portanto, que esses grupos sociais inventam e reinventam práticas culturais, como acontecimentos que se revelam por meio das relações, interações e trocas entre os sujeitos praticantespensantes que, usando táticas cotidianas, resistem à ordem vigente. Compreendemos que a prática cultural do Encontro, como acontecimento reinventado; e a Prática do Boi Leão, como acontecimento de resistência, assim como outras práticas culturais de outros contextos, podem constituir-se como pontos de partida para produção de conhecimentos e de sentidos na escola, acerca dos problemas e diálogos estabelecidos por um grupo ou por pessoas em interação -, como exemplo, os moradores do Vale do Reginaldo. Essa interação é possível em razão dos elementos sociais e culturais em comum, ou mesmo diferentes de um grupo, mas que geram diálogos, problematizações e compreensões.

No caso específico do Vale do Reginaldo, os encontros (re)inventados e a prática de resistência resultaram em mudanças de comportamentos dos seus moradores e dos estudantes no contexto escolar. Esses acontecimentos mantiveram-se como práticas interacionais que permitiram/permitem as trocas de experiências e discussões sobre os problemas locais, e criação de resistências para as mudanças estruturais que vivem o Reginaldo, bem como para vivenciarem outros acontecimentos do cotidiano.

Embora esses sujeitos sejam compreendidos apenas enquanto consumidores por uma elite que acredita ter e produzir uma cultura "verdadeira" e, terem tais sujeitos o status de dominados, eles não são sujeitos passivos e dóceis. $\bigcirc$ cotidiano nos mostrou que as práticas culturais de resistência são criadas, mesmo que essas criações não sejam legitimadas, oficialmente, por aqueles que acreditam ter o poder absoluto no espaço do Vale do Reginaldo e na escola. 


\section{Notas}

1 Os termos juntos utilizados neste texto, referem-se ao entendimento nos escritos de Alves (2003), aliados a grupos de pesquisas sobre os estudos no/do/com o cotidiano, que indicam os limites das dicotomias teóricas e práticas, criadas pelas ciências na Modernidade, mostrando que os elementos desses estudos devem apresentar-se como processuais.

2 Este artigo é um recorte de uma pesquisa que teve como objeto de estudo as práticas culturais, realizada no âmbito do PROCAD/Casadinho (CNPq 201 2-2014), projeto que envolve a UFAL/ UERJ/UFRN.

\section{Referências}

ALVES, Nilda. Cultura e cotidiano escolar. Revista Brasileira de Educação, Rio de Janeiro, n. 23, p. 62-74, maio/ago. 2003.

ALVES, Nilda; GARCIA, Regina Leite. Prefácio - Continuando a conversa. In: FERRAÇO, Carlos Eduardo; PEREZ, Carmem Lúcia Vidal; OLIVEIRA, Inês Barbosa de Oliveira (Org.). Aprendizagens cotidianas com pesquisa - novas reflexões em pesquisa nos/dos/com os cotidianos das escolas. Petrópolis: DP et Alii, 2008.

BAKHTIN, Mikhail. Marxismo e filosofia da linguagem. 6. ed. São Paulo: Hucitec, 1992.

CERTEAU, Michel de. A invenção do cotidiano: morar, cozinhar. 10. ed. Petrópolis: Vozes, 2011 . (v. 2).

A cultura no plural. 7. ed. Campinas: Papirus, 2012.

A invenção do cotidiano: 1. arte de fazer. 20. ed. Petrópolis: Vozes, 2013.

DIRETORA. Entrevista. Maceió (Alagoas), 3 jun. 2013.

DONA APARECIDA. Entrevista. Maceió (Alagoas), 12 set. 2012.

DONA DÉ. Entrevista. Maceió (Alagoas), 13 jun. 2013.

FREITAS, Antonio Francisco. O diálogo em sala de aula - análise do discurso. Curitiba: HD Livros Editora, 1999.

GINZBURG, Carlo. O queijo e os vermes. $O$ cotidiano de um moleiro perseguido pela inquisição. São Paulo, Companhia das Letras, 2006.

GOMES, Duarte. Cultura organizacional: comunicação e identidade. Coimbra: Quarteto Editora, 2000. 
HALL, Stuart. Da diáspora - identidades e mediações culturais. Belo Horizonte: Editoras UFMG, 2013.

OLIVEIRA, Inês Barbosa de. O currículo como criação cotidiana. Petrópolis: DP et Alii; Rio de Janeiro: FAPERJ, 2012.

PINHEIRO, Rosa Aparecida. Formação de educadores de jovens e adultos no Programa Geração Cidadã: relação entre saberes na proposição curricular. 2007. 220f. Tese (Doutorado em Educação) - Programa de Pós-Graduação em Educação, Universidade Federal do Rio Grande do Norte, Natal, 2007.

SAMPAIO, Carmen Sanches. Pesquisa com o cotidiano e as opções interessadas da ação pesquisadora. In: FERRAÇO, Carlos Eduardo; PEREZ, Carmem Lúcia Vidal; OLIVEIRA, Inês Barbosa de Oliveira. Aprendizagens cotidianas com pesquisa - novas reflexões em pesquisa nos/dos/com os cotidianos das escolas. Petrópolis: DP et Alii, 2008.

SOUZA, Cassia Garcia de; MENEGHELLO, Marinez; PASSOS, Angela; PINELA, Thatiane; GIARETTA, Liz Andréia; BELLUSCI, Simoni; SOSSO, Juliana. É bom aprender: língua portuguesa, matemática, ciências, história, geografia e artes. Educação de Jovens e Adultos - EJA. São Paulo: FTD, 2009. (v. 2).

SR. MARCOS DA ASSOCIAÇÃO. Entrevista. Maceió (Alagoas), 3 jun. 2013.

SR. MARCOS 1. Entrevista. Maceió (Alagoas), 29 ago. 2013.

SR. PAULO. Entrevista. Maceió (Alagoas), 3 jun. 2013.

TORRES, Leonor Lima. Escola como entreposto cultural: o cultural e o simbólico no desenvolvimento democrático da escola. Revista Portuguesa de Educação, Braga (Portugal), v. 21 , n. 1, p. 59-81, 2008.

TURA, Maria de Lourdes Rangel. Conhecimentos escolares e a circularidade entre culturas. In: LOPES, Alice Casimiro; MACEDO, Elizabeth (Org.). Currículo: debates contemporâneos. São Paulo: Cortez, 2010.

Profa. Dra. Marinaide Lima de Queiroz Freitas

Universidade Federal de Alagoas

Centro de Educação

Programa de Pós-Graduação em Educação Brasileira 
Artigo

Da comunidade à escola: desvelando práticas culturais (in)visíveis dos sujeitos praticantespensantes

Grupo de Pesquisa Multidisciplinar em Educação de Jovens e Adultos | Multieja | $\mathrm{CNPq}$ E-mail | naide12@hotmail.com

Profa. Dra. Elisabete Duarte de Oliveira Instituto Federal de Alagoas

Coordenação das Licenciaturas Grupo de Pesquisa Multidisciplinar em Educação de Jovens e Adultos | Multieja | $\mathrm{CNPq}$ E-mail | elisabete.ifal@gmail.com

Recebido 28 ago. 2016 Aceito 13 set. 2016 